\title{
Investigation of Polarimetric SAR Data Acquired at Multiple Incidence Angles
}

\section{Svendsen, Morten Thougaard; Skriver, Henning; Thomsen, A.}

Published in:

Geoscience and Remote Sensing Symposium Proceedings, 1998. IGARSS '98. 1998 IEEE International

Link to article, DOI:

10.1109/IGARSS.1998.692454

Publication date:

1998

Document Version

Publisher's PDF, also known as Version of record

Link back to DTU Orbit

Citation (APA):

Svendsen, M. T., Skriver, H., \& Thomsen, A. (1998). Investigation of Polarimetric SAR Data Acquired at Multiple Incidence Angles. In Geoscience and Remote Sensing Symposium Proceedings, 1998. IGARSS '98. 1998 IEEE International (Vol. 3, pp. 1720-1722). IEEE. https://doi.org/10.1109/IGARSS.1998.692454

\section{General rights}

Copyright and moral rights for the publications made accessible in the public portal are retained by the authors and/or other copyright owners and it is a condition of accessing publications that users recognise and abide by the legal requirements associated with these rights.

- Users may download and print one copy of any publication from the public portal for the purpose of private study or research.

- You may not further distribute the material or use it for any profit-making activity or commercial gain

- You may freely distribute the URL identifying the publication in the public portal 


\title{
Investigation of Polarimetric SAR Data Acquired at Multiple Incidence Angles
}

\author{
Morten T. Svendsen ${ }^{1,2}$, Henning Skriver ${ }^{1}$, and Anton Thomsen ${ }^{2}$ \\ ${ }^{1}$ Danish Center for Remote Sensing, Dept. of Electromagnetic syst. \\ Technical University of Denmark, Building 348, DK-2800 Lyngby, Denmark. \\ Phone: +45 4588 1444, Fax: +45 4593 1634, E-mail: mts@emi.dtu.dk \\ ${ }^{2}$ Danish Institute of Agricultural Sciences, \\ Research Centre Foulum, DK-8830 Tjele, Denmark
}

\begin{abstract}
The dependence of different polarimetric parameters on the incidence angles in the range of $30^{\circ}$ to $60^{\circ}$ is investigated for a number of different crops using airborne SAR data. The purpose of the investigation is to determine the effect of the variation of incidence angle within a SAR image when using different polarimetric parameters for crop classification and parameter retrieval algorithms.
\end{abstract}

\section{INTRODUCTION}

During the 1997 growing season two airborne SAR campaigns ${ }^{1}$ were conducted at the Danish agricultural test site Foulum using the Danish EMISAR ${ }^{2}$ system. At each campaign L- and Cband data were acquired covering the same area at four different incidence angles. From each of the acquired SAR images different polarimetric parameters were estimated for a number of different fields.

Estimating the parameters from SAR data gives only a few time samples and typically only one incidence angle for a certain position in the scene, because each sample involves acquiring and processing of an entire SAR scene. On the other hand, it allows simultaneous investigation of many fields, it allows the samples to be averaged over a large number of pixels to reduce the influence of speckle, and it allows evaluation of the effect of texture and within field inhomogeneities.

The campaigns are part of a crop monitoring study carried out at the Danish Center for Remote Sensing (DCRS) in cooperation with Danish Institute of Agricultural Sciences (DIAS) at Research Rentre Foulum (RCF) which is a research center under the Danish Ministry of Agriculture.

\footnotetext{
${ }^{1}$ The data acquisitions, data processing and data interpretation have been sponsored by the Danish National Research Foundation and the Danish Space Board.

${ }^{2}$ Development of the EMISAR ha been co-sponsored by Thomas B. Thriges fond, the Danish Technical Research Council (STVF), The Royal Danish Air force and the Joint Research Centre.
}

\section{DATA ACQUISITIONS}

SAR data were acquired on April 9 (L-band), April 10 (Cband), June 3 (L-band) and June 4 (C-band) at the Foulum test site, which is located in the northern part of Jutland around RCF and covers an area mainly consisting of farmland.

The SAR data were acquired with the EMISAR system [1], which is an L- and C-band, fully polarimetric SAR system, developed at DCRS since 1986. The SAR system is installed on a Danish Air Force Gulfstream aircraft, and has a spatial resolution of $2 \mathrm{~m}$ by $2 \mathrm{~m}$. The ground range swath is approximately $12 \mathrm{~km}$ and the incidence angle typically ranges from $30^{\circ}$ to $60^{\circ}$ across the swath. The processed data from this system are fully calibrated.

The SAR acquisitions were carried out so that a number of large, relatively flat and homogeneous fields, selected for this campaign, were covered at four different incidence angles within the range of incidence angles typical for the EMISAR system, so that the effect of the variation of the incidence angle within an image can be evaluated.

The selected fields were subject to extensive in-situ measurements simultaneously with the SAR acquisitions. Soil moisture and roughness parameters were measured along with a number of plant parameters for each of the considered crop types to help interpretation of the SAR data and to provide a set of input data for theoretical EM-backscatter models, for which the SAR data set can serve as validation.

\section{POLARIMETRIC FEATURES}

Apart from the information about the scattering medium from the co- and cross-polarized backscatter intensities, $\sigma_{h h}^{0}, \sigma_{h v}^{0}$, and $\sigma_{v v}^{0}$, additional information can be achieved from the correlation between these. The correlation between the co- and cross polarization channels is small for most natural targets and often ignored. The correlation between the co-polarized channels is parametrized by the amplitude of the HH-VV correlation coefficient $\rho_{h h v v}$ and the HH-VV polarization phase 
difference $\Psi_{h h v v}$, defined in terms of the the elements of the complex scattering matrix $S$ by

$$
\begin{gathered}
\rho_{h h v v}=\frac{\left|E\left[S_{h h} S_{v v}^{*}\right]\right|}{\sqrt{E\left[\left|S_{h h}\right|^{2}\right] E\left[\left|S_{v v}\right|^{2}\right]}} \\
\Psi_{h h v v}=\operatorname{Arg}\left(E\left[S_{h h} S_{v v}^{*}\right]\right)
\end{gathered}
$$

A different approach to utilize the information from the entire polarimetric data set, has been presented by Cloude [2]. It is a decomposition scheme applicable for extended and/or random targets, and in this approach no assumptions are made about correlation between the co- and cross polarized backscatter. The Cloude decomposition is based on an eigen value/eigen vector analysis of the coherency matrix $T$ to extract information about the dominating scattering mechanism. Considering the backscattering case the coherency matrix is a $3 \times 3$ Hermetian matrix, defined by:

$T=\left\langle\left(S_{h h}+S_{v v} S_{h h}-S_{v v} 2 S_{h v}\right)\left(S_{h h}+S_{v v} S_{h h}-S_{v v} 2 S_{h v}\right)^{T *}\right\rangle$

The eigen values $\lambda_{1}, \lambda_{2}$, and $\lambda_{3}$ of $T$ are therefore real, whereas its eigen vectors $v_{1}, v_{2}$, and $v_{3}$ generally are complex. The polarimetric entropy is defined as

$$
H=\sum_{i=1}^{3}-P_{i} \log _{3} P_{i} \quad P_{i}=\frac{\lambda_{i}}{\sum_{j=1}^{3} \lambda_{j}}
$$

Normalizing the eigen vectors $\mathbf{v}_{i}$ they can be parametrized as

$$
\mathbf{v}_{i}=\left[\begin{array}{lll}
\cos \alpha_{i} & \sin \alpha_{i} \cos \beta_{i} e^{\delta_{i}} & \sin \alpha_{i} \sin \beta_{i} e^{\gamma_{i}}
\end{array}\right]
$$

and a mean $\alpha$ parameter is defined by

$$
\alpha=P_{1} \alpha_{1}+P_{2} \alpha_{2}+P_{3} \alpha_{3}
$$

This gives a feature vector $(H, \alpha)$, which is used to characterize the scattering properties, and is suggested for an unsupervised classification scheme.

\section{RESULTS AND DISCUSSION}

The dependence of the four considered parameters: The HHVV phase difference, $\Psi_{h h v v}$, the HH-VV correlation coefficient $\rho_{h h v v}$, the polarimetric entropy, $H$, and the $\alpha$ parameter on the incidence angle is investigated by estimating the parameters from the SAR data at both L- and C-band for three different areas: $A$ bare field, a spring barley field and a rye field.

For the bare field, SAR data from the April campaign were used to estimate the parameters. For the spring barley field and the rye field, SAR data from the June acquisitions were used. At the time of these acquisitions, the spring barley field had a height of $35 \mathrm{~cm}$ and the rye field had a height of $89 \mathrm{~cm}$.

The considered fields contain each more than 50.000 pixels within the SAR image. Although the pixels are correlated this makes the error due to speckle insignificant.
Fig. 1 shows the dependence of the HH-VV phase difference on the incidence angle for the selected fields. It is observed, that the dependence of the HH-VV phase difference on the incidence angle is significantly larger for vegetated fields at $\mathrm{L}$ band than for unvegetated fields or for $\mathrm{C}$-band.

At L-band the two-way attenuation by the vegetation layer of backscatter from the ground below the vegetation layer will result in a negative phase difference, whereas the backscatter from the plant-ground double bounce reflection will result in a positive phase difference [3]. The phase difference of the total backscatter then depends on the portion of backscatter from each of these two mechanisms. In the case, where only a minor part of the incident electromagnetic field penetrates to the ground, the phase difference will be smaller and have less variation with incidence angle. This is the case for the $\mathrm{C}$-band data for the vegetated fields, where the HH-VV phase difference is a slightly increasing function of the incidence angle for the vegetated fields. It is also noted, that for the bare field an increasing phase difference is observed for $\mathrm{C}$-band and a decreasing for L-band as a function of incidence angle. Similar results have been reported for measurement of backscatter from bare soils using a truck mounted scatterometer [4].

As we would expect from the definition of the polarimetric entropy and the HH-VV correlation coefficient, the figs. 2 and 3 suggest, that these two parameters for the considered areas are related. When the polarimetric entropy is an increasing function of the incidence angle, the HH-VV correlation coefficient is decreasing. For most of the considered areas the HHVV correlation coefficient is a slowly decreasing function of the incidence angle.

At C-band the HH-VV correlation coefficient is largest for the bare soil field, where the backscatter is mainly due to surface scattering. For the spring barley and rye fields, the vegetation cover induces multiple scattering and different penetration for different polarizations, which results in the smaller correlation coefficient. At L-band the HH-VV correlation coefficient is smallest for the spring barley field, and largest for bare soil or rye depending on the incidence angle. What causes the large decorrelation for the bare soil and the smaller decorrelation for the rye field at large incidence angles, is still to be examined.

The dependence of the $\alpha$ parameter on the incidence angle is shown in fig.4. For most of the considered areas the $\alpha$ parameter is an increasing function of the incidence angle. For the rye field at L-band the $\alpha$ parameter, however, drops significantly around $45^{\circ}$ incidence, which is at the same incidence angle, the HH-VV phase difference crosses zero. The small HH-VV phase difference makes the dominating scattering mechanism resemble surface scattering, for which the $\alpha$ parameter is small. This probably results in the drop in the value of $\alpha$.

\section{CONCLUSIONS}

The dependence of a number of different polarimetric parameters on the incidence angle has been determined at two times 
HH-W Phase difference

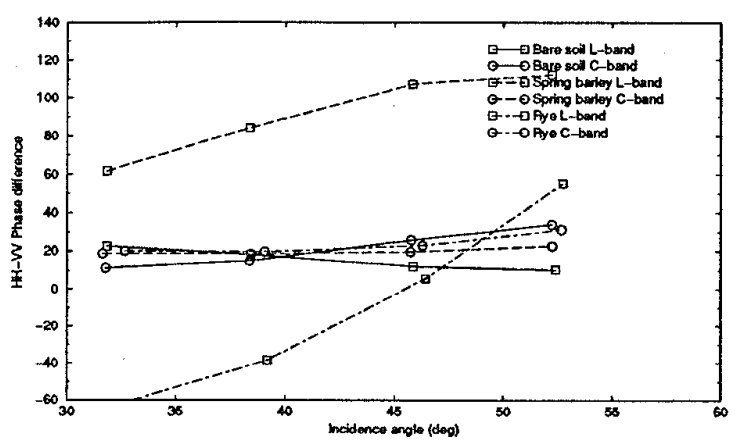

Figure 1: HH-VV Phase difference estimated from SAR images, acquired in April and June at L- and C-band.

HH-W correlation coefficient

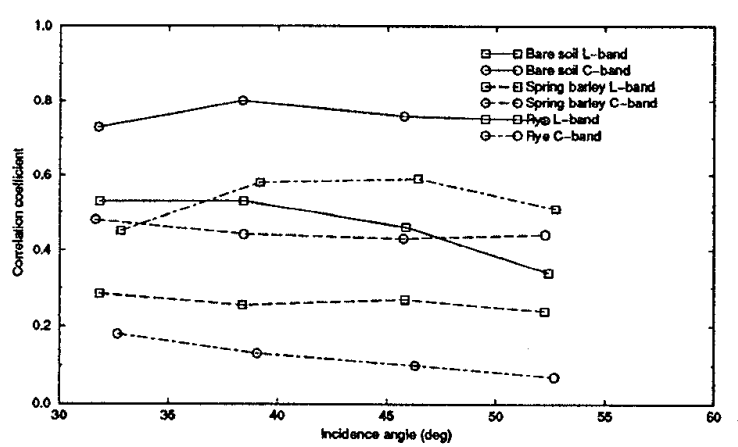

Figure 2: HH-VV Correlation coefficient estimated from SAR images, acquired in April and June at L- and C-band.

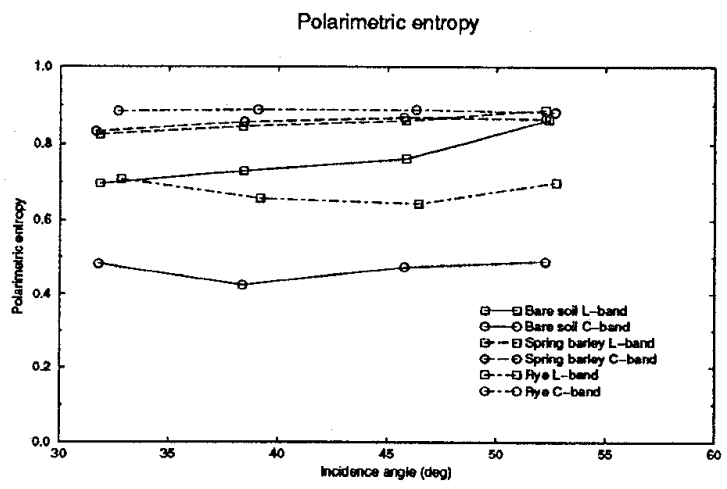

Figure 3: Polarimetric entropy estimated from SAR images, acquired in April and June at L- and C-band.

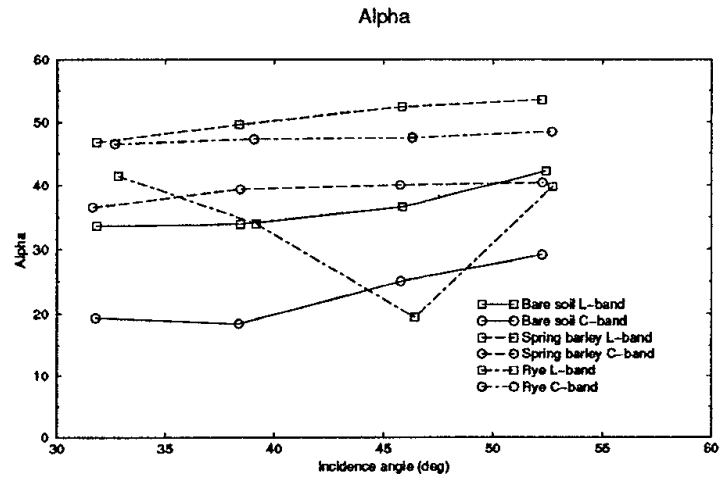

Figure 4: The $\alpha$ parameter estimated from SAR' images, acquired in April and June at L- and C-band.

during the growing season at both L- and C-band. The HH-VV phase difference and the $\alpha$ parameter may at $\mathrm{L}$-band for vegetated areas exhibit a strong dependence on the incidence angle, which has to be considered before using these parameter for crop type classification. The HH-VV correlation coefficient and the polarimetric entropy depend for the considered areas only weakly on the incidence angle, and less care is needed when using these parameters.

\section{ACKNOWLEDGMENTS}

The authors would like to thank Wolfgang Dierking, DCRS, for useful comments on the manuscript, and Flemming Nielsen, DIAS, for assistance with the in-situ measurements.

\section{REFERENCES}

[1] E. L. Christensen, N. Skou, J. Dall, K. Woelders, A. Netterstrøm, J. H. Jørgensen, J. Granholm, and S. N. Madsen, "EMISAR: Polarimetric L- and C-band SAR", accepted for IEEE Trans. Geosci. Remote Sens., 1998.

[2] R. S. Cloude and E. Pottier, "An Entropy based Classification Scheme for Land Applications of Polarimetric SAR", IEEE Trans. Geosci. Rem. Sens. vol. 35, 1997, pp. 68-78.

[3] F. T. Ulaby, D. Held, M. C. Dobson, K. C. McDonald, and T. B. A. Senior, "Relating Polarization Phase Difference of SAR Signals to Scene Properties", IEEE Trans. Geosc. Rem. Sens. vol. 25, 1987, pp. 83-91.

[4] K. Sarabandi, Y. Oh, and F. T. Ulaby, "Measurement and Calibration of Differential Mueller Matrix Distributed Targets", IEEE Trans. Ant. Prop., vol. 40, 1992, pp. 15241532. 